\title{
Summer soil-precipitation coupling in South America
}

\author{
By ANNA A. SÖRENSSON ${ }^{1 *}$ and CLAUDIO G. MENÉNDEZ ${ }^{1,2}, \quad{ }^{1}$ Centro de Investigaciones \\ del Mar y la Atmósfera, CONICET/UBA, Buenos Aires, Argentina; ${ }^{2}$ Departamento de Ciencias de la Atmósfera \\ y los Océanos, FCEN, UBA, Buenos Aires, Argentina
}

(Manuscript received 7 September 2009; in final form 14 May 2010)

\begin{abstract}
The soil moisture memory contributes to atmospheric variability and seasonal predictability and could potentially affect the development of the South American Monsoon System. The relative importance of the local land surface feedbacks and the large-scale dynamical processes during the different phases of the monsoon are still largely unknown. We examine the impacts of land surface conditions during the mature monsoon phase with the Rossby Centre Atmospheric regional model through calculating the coupling strength between soil moisture, evapotranspiration and precipitation. Regions of high coupling strength (hotspots) are identified and analysed focusing on the link between soil moisture-evapotranspiration coupling and soil moisture-precipitation coupling, the relation between the coupling strength and seasonal predictability and the hotspots importance for extreme precipitation events. La Plata Basin and northeastern Brazil are identified as hotspots due to evapotranspiration recycling. A region within the South Atlantic Convergence Zone is identified as a hotspot of precipitation explained by moisture advection. Extreme precipitation events are repressed in parts of La Plata Basin when the link between precipitation and soil moisture is cut through using prescribed soil moisture.
\end{abstract}

\section{Introduction}

The region of this study is South America, which has a wide range of tropical and extratropical climatic conditions, with areas of radip land use change, and a population vulnerable to climatic variability. The South American continent has contrasting geographical features, ranging from the world's largest rain forest in Amazonia to the driest desert in northern Chile and an elevated desert in the Altiplano. The high and steep Andes Mountains rise along the Pacific coast on the west. Eastern South America is characterized by the presence of large river basins, such as the Amazon and the La Plata basins. Patagonia is the southernmost continental portion, embedded in the Southern Ocean near the circumpolar band of low pressure. The La Plata basin region in Southeastern South America is densely populated, with $50 \%$ of the total population and $70 \%$ of the Gross National Product of Argentina, Brazil, Uruguay, Paraguay and Bolivia.

In tropical and subtropical latitudes a warm season precipitation maximum, associated with the South American Monsoon

\footnotetext{
*Corresponding author.

CIMA/CONICET/UBA, Pabellón 2, Piso 2, Ciudad Universitaria

(1428), Buenos Aires, Argentina

e-mail: sorensson@cima.fcen.uba.ar

DOI: $10.1111 / \mathrm{j} .1600-0870.2010 .00468 . x$
}

System (SAMS), dominates the mean seasonal cycle of precipitation (Nogués-Paegle et al., 2002; Vera et al., 2006a). The timing of its onset and duration, as well as the intensity and spatial distribution of daily rainfall have important implications for agriculture and hydroelectric power generation throughout tropical and subtropical South America.

The land-ocean thermal contrast and the continental latent heat flux release contribute to the determination of the onset, the intensity and spatial distributions of monsoons (Webster et al., 1998). The soil moisture memory could potentially affect the development of the SAMS through its influence on the partitioning between sensible and latent heat fluxes. In a study using ERA15 data, Fu and Li (2004) and Li and Fu (2004) found that the continental surface conditions seem to control the onset date of the monsoon (the onset date was defined on basis of daily mean rainfall exceeding the threshold of $6.1 \mathrm{~mm}$ ). Increments of evapotranspiration and local water recycling are necessary for the onset, while during the later developing and mature phases, both surface water fluxes and moisture transport from the Atlantic are important. Collini et al. (2008) showed similarly that October precipitation was more responsive to reductions than to increases in initial soil moisture using a regional climate model (RCM). They found that reductions in initial soil moisture produced almost linear reductions in precipitation over the monsoon region, principally because of the increase of the Bowen ratio that reduced the atmospheric instability. In a 
recent review paper on the SAMS, Vera et al. (2006a) identified land surface processes and their relative role in the development of the SAMS as a as a major research question to be addressed in order to achieve a better understanding of the monsoon system.

The feedback processes between soil moisture and precipitation are difficult to assess in terms of causality due to the many complex feedbacks between the components of the system, such as radiation budget, boundary layer development and land surface fluxes. In this paper, the influence of soil moisture on evapotranspiration and precipitation is studied through an experimental design that isolates this connection from the impact of precipitation anomalies on soil moisture anomalies. The quantified influence of soil moisture on evapotranspiration or precipitation is called coupling strength (CS). In general terms, CS is defined as the relative influence of some prescribed boundary condition, for example sea surface temperature (SST) or soil moisture, on some atmospheric variable in a climate model. Several recent studies focus on the CS between soil moisture and precipitation and/or surface variables such as temperature and evapotranspiration (Koster et al., 2003, 2004, 2006; Dirmeyer et al., 2006; Guo et al., 2006; Seneviratne et al., 2006; Wang et al., 2007; Yamada et al., 2007). These authors use somewhat different approaches but all aim to quantify the fraction of atmospheric variability that can be ascribed to soil moisture anomalies. Almost all these studies have concentrated on the Northern hemisphere summer, a season where soil moisture-atmosphere coupling could be comparable or even stronger than SST-atmosphere coupling for mid-latitudes (e.g. Dirmeyer 2003).

The coupling between soil moisture and precipitation should not only be thought of as a result of local water recycling, in the sense that the precipitation at each grid cell originates from the same grid cell trough evapotransporation (as in Elthair and Bras 1994, 1996; Trenberth 1999). This process contributes to the CS, but is not identified separately here. Instead the CS should be understood as how the soil moisture field influences on the fields of evapotranspiration and precipitation. This is a result of non-linear interactions within a climate model, including components such as moisture transport, parametrizations of evapotranspiration, moist convection and boundary layer development. The water vapour that rains out does not necessarily come from the grid box where it evaporated, but can as well be advected from its origin to a grid box of highly favourable conditions for rainfall.

The effect of soil moisture on the surface fluxes and consequently on the Bowen ratio can lead to changes in precipitation (e.g. Betts and Viterbo, 2005; Taylor and Ellis, 2006). Collini et al. (2008) discuss the local effects that soil moisture anomalies have on the overlying atmosphere during the early stages of development of the SAMS. Reduction of the soil moisture gives rise to changes in the boundary layer structure and thermodynamic stability: the increased sensible heat flux and reduc- tion of latent heat flux (evapotranspiration) favour mixing and a warmer, deeper and drier boundary layer. These changes affect the convective instability: the convective available potential energy (CAPE) is reduced while the convective inhibition (CIN) is increased slightly (resistance to convection). These effects are dependent on numerous factors including the time of day (effects described in Collini et al. (2008) are most apparent during daytime), the time of year (Silva and Berbery (2006) found little relation between the monsoon precipitation and CAPE during the austral summer months when the SAMS is already established), the spatial-scale of convective systems (Taylor and Ellis, 2006) and the land cover types (Juang et al., 2007).

Within the GLACE project (e.g. Koster et al., 2003, 2004, 2006; Guo et al., 2006), the CS between soil moisture and atmosphere for 16 global atmospheric models was explored over the northern hemisphere for boreal summer. They showed that global models vary substantially in CS, both in global averages and in spatial distribution. This implies that, e.g. sensitivity to soil moisture anomalies is highly model dependent.

The aim of this study is to document the degree to which the precipitation responds to soil moisture anomalies during the SAM in Rossby Centre Atmospheric regional model (RCA3, Samuelsson et al., 2011). The coupling between soil moisture and atmosphere is still largely unknown for South America and it is a very uncertain aspect of regional modelling. The model experiments were realized for the season DJF of 1992-1993. The period was chosen to be able to compare the results from other studies, such as Koster et al. (2006) that calculated CS for boreal summer (JJA) and Wang et al. (2007) that calculated CS for both boreal and austral summer. It is also the season where RCA3-E precipitation is well representated in La Plata Basin. Two different indices were calculated and compared with the purpose of identifying regions of strong coupling between soil moisture and precipitation in the regional model. In Section 2, the performance of RCA3-E over South America is discussed. In Section 3 the experiment set up and the CS indices employed in this study are described. In Section 4, we present the results focusing on the link between soil moisture, evapotranspiration coupling and precipitation coupling, the relation between the CS and the predictability and the importance for extreme precipitation events. Finally, conclusions are given in Section 5.

\section{The regional model and its performance over South America}

In this study we use RCA3-E, which is the official version of RCA3 modified to improve the performance for tropical and subtropical climates. Samuelsson et al. (2011) gives a detailed description of RCA3 and its land surface scheme. The differences between RCA3 and RCA3-E are the following. The database Ecoclimap (Champeaux et al., 2005) was implemented to obtain 
a more accurate description of the land surface. The features of Ecoclimap that are most important for the representation of the South American climate are the soil depth and leaf area index (Sörensson et al., 2009). The Kain and Fritsch (1993) convection has been modified with a trigger function from Rogers and Fritsch (1996) and, in the CAPE closure, a diluted updraft profile is used instead of an undilute one (Kain, 2004) and the entrainment and detrainment factors are hardcoded to 0.5 each. With respect to the microphysics, the conversion of liquid water to rain was changed from the Chen and Cotton (1987) approach to the Khairoutdinov and Kogan (2000). The model domain covers the South American continent, and is based on a rotated grid system with a horizontal resolution of $0.5^{\circ}$ and 24 unevenly spaced sigma levels in the vertical with the five lowest levels below 900 $\mathrm{hPa}$.

For the purpose of model evaluation, we performed a 20-yr simulation of present climate (1980-1999 with $1 \mathrm{yr}$ of spinup) with initial and boundary conditions from the European Centre for Medium-Range Weather Forecasts 40-yr Reanalysis (ERA-40, Uppala et al., 2005). The simulated precipitation was evaluated against high-resolution $\left(0.5^{\circ} \times 0.5^{\circ}\right)$ precipitation data compiled by the Climatic Research Unit (CRU) of the University of East Anglia (New et al., 1999, 2000). Some caveats should be pointed out concerning this data set over South America since over large regions, such as Amazonia, the central Andes and Patagonia the station density is low. Consequently the interpolation procedure used in developing the CRU data set might affect the fine scale structure of the actual field, although our analysis of broad structures compensates partly for this.

In comparison to CRU data, RCA3-E captures many aspects of the observed annual mean precipitation based on the CRU data (Fig. 1). However, it underestimates the rainfall over parts of northern Amazonia and central Brazil, as well as some areas of southeastern South America: southern Brazil, Uruguay and northeastern Argentina. The precipitation is overestimated in parts of northern Brazil (around $5^{\circ} \mathrm{S}$ ), western Amazonia and along the Andes. The precipitation over the Andes is difficult to assess due to the complex topography of the steep Andes and the sparse observational data used for the CRU compilation in this region (New et al., 1999). On the seasonal scale RCA3-E shows an acceptable representation of the large-scale patterns, although in tropical regions, the maximum intensities are overestimated (Sörensson, 2010). The JJA local maximum in La Plata Basin is underestimated, a common bias of both reanalysis driven RCMs (Menéndez et al., 2010) and coupled general circulation models (e.g. Vera et al., 2006b). The model simulates quite well the 20-yr mean annual cycle and the interannual variability for each season, as well as the 20 -yr annual mean time series for most regions (not shown). The underestimation of rainfall during winter, especially in the Amazonia and in the La Plata Basin produces warm biases with a lag of a month to a season, in part due to a delayed feedback between precipitation and deep soil moisture (Sörensson, 2010).
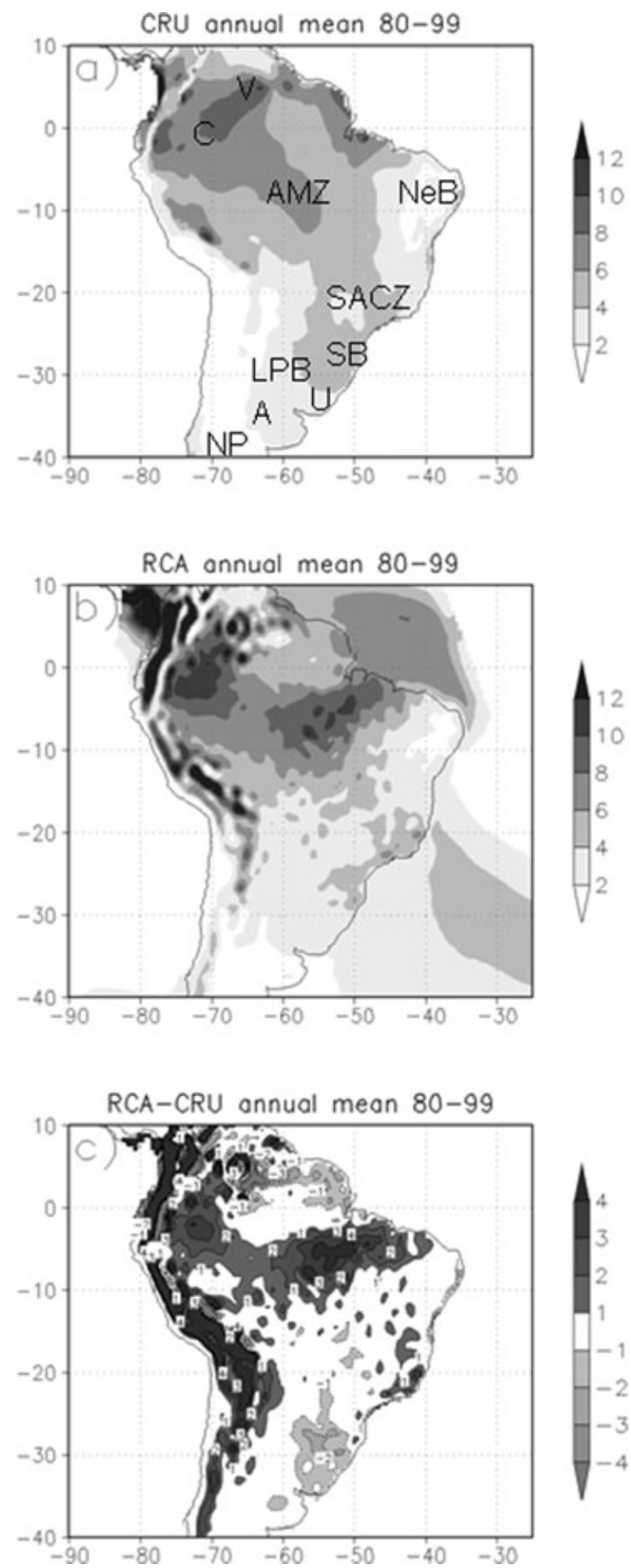

Fig. 1. Annual-mean precipitation $\left(\mathrm{mm} \mathrm{d}^{-1}\right)$ January 1,1980 to December 31, 1999. (a) CRU, (b) RCA3-E, (c) RCA3-E minus CRU. In (a) some geographical references are given: V, Venezuela; $C$, Colombia; AMZ, Amazonia; NeB, northeastern Brazil; SACZ, South Atlantic Convergence Zone; SB, Southern Brazil; U, Uruguay; A, Argentina and NP, Northern Patagonia. 


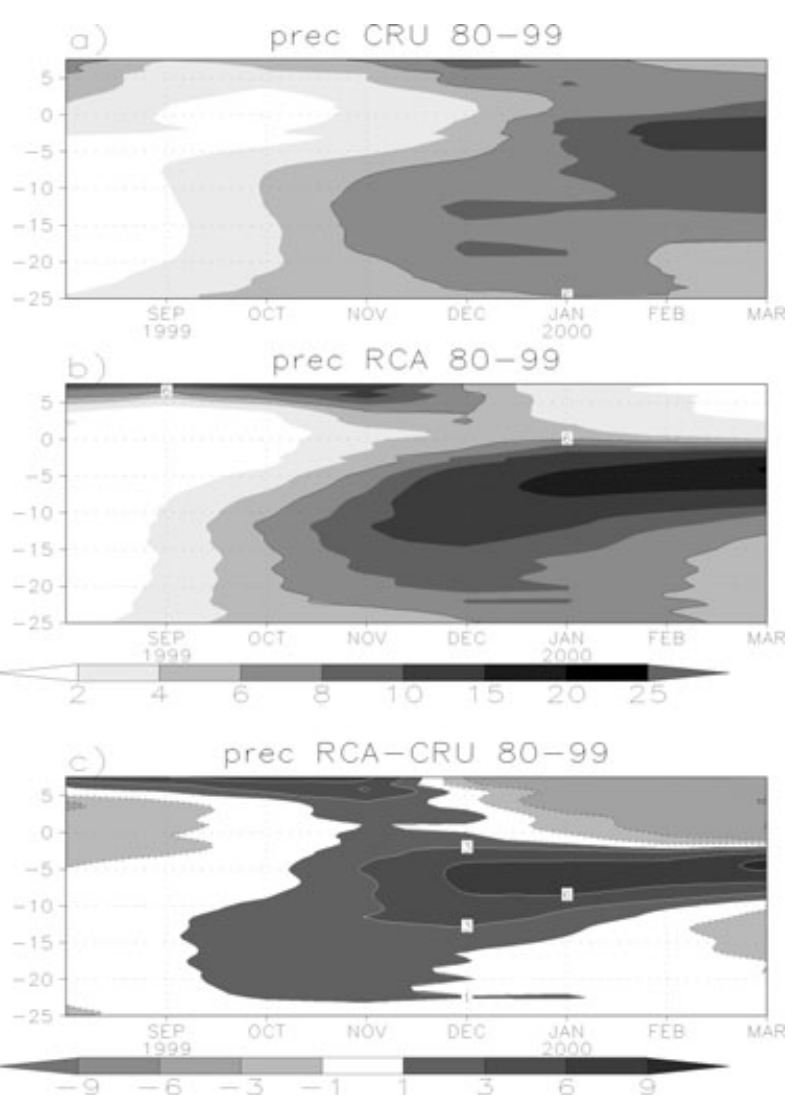

Fig. 2. Temporal evolution of the monthly mean precipitation $\left(\mathrm{mm} \mathrm{d}^{-1}\right)$ averaged over $40^{\circ}-60^{\circ} \mathrm{W}$ (land only) from August 1 to March 31 (1980-1999): (a) CRU, (b) RCA3-E and (c) RCA3-E minus CRU. Vertical axis shows latitudes.

To outline more clearly the monsoon evolution we show the monthly mean precipitation for the $20 \mathrm{yr}$ of simulation, zonally averaged (over land only) between $60^{\circ} \mathrm{W}$ and $40^{\circ} \mathrm{W}$ from August to March (Fig. 2). The regional model simulates an early onset of the monsoon (see e.g. the isohyet of $6 \mathrm{~mm} \mathrm{~d}^{-1}$ as a reference) at almost all latitudes south of the equator. Between $0^{\circ}$ and $10^{\circ} \mathrm{S}$ the precipitation increases rapidly and obtains too high values from November to March. North of the equator a precipitation maximum occurs in December in CRU while in RCA the maximum occurs in October-November and the model then dries out from December to March. South of $10^{\circ} \mathrm{S}$ RCA has a better performance for the whole period.

Overall the main large-scale spatial patterns of annual and monthly precipitation for South America exhibit a reasonably good agreement with observations. This allows us to pursue this study with some confidence in the realism of the results. Because South America is surrounded by the data-poor ocean, the model skill is affected by uncertainties in the lateral boundary conditions used to drive the model. Moreover, the specification of the model skill is also subject to uncertainties in the observationally based data sets used to evaluate the model.

\section{Methodology}

\subsection{General experiment set up}

The methodology has been adapted to regional modelling following Koster et al. (2006), with the difference that the model was forced with both top and deep soil moisture instead of only by deep soil moisture.

Two ensembles of ten members each were created (called W and S), starting from different initial dates. Each member extends over a period of $120 \mathrm{~d}$ from November 1, 1992 to March 31 1993. An analysis of the time evolution of the soil moisture of a multiyear integration with RCA3-E initialized and forced by ERA-40 showed that the soil moisture spin-up time can be up to $2 \mathrm{yr}$ for regions with deep rooting depth as Amazonia. In order to initialize the regional model with the atmosphere-soil moisture in equilibrium, the soil moisture initial conditions (meter of water per meter of soil) are set to the soil moisture fields of corresponding initial date from a RCA3-E/ERA-40 integration initialized on the September 1, 1990. All other initial and boundary conditions are from ERA-40.

Ensemble W: Model with a full land surface-atmosphere interaction. The soil moisture is calculated by the model at each time step and the only difference between members is the initialization date.

Ensemble S: The ensemble members are forced, at each time step, to maintain the same space-time varying series of top and deep soil moisture. This series is obtained from a previous simulation of the period from which top and deep soil moisture had been saved every $30 \mathrm{~min}$ (model time step). Consequently, between the soil moisture and other components of the system, and in particular the water budget, there is only a one-way interaction. The soil moisture affects variables like precipitation, evapotranspiration and surface temperature, but these variables do not feed back upon soil moisture.

Since the initial dates and the lateral boundary forcings as well as the SST are the same for the two ensembles, the only difference between ensemble $\mathrm{W}$ and $\mathrm{S}$ is that in $\mathrm{W}$, there is fully interaction between soil moisture and the atmosphere, while in $\mathrm{S}$, the soil moisture is a boundary condition and, e.g. a day of heavy precipitation will not increase the soil water content.

As a cautionary note, the selection of the reference series of soil moisture (which could be relatively 'dry' or 'wet') in the S ensemble might have an impact on the ensemble spread (this effect was not quantified in this study). Another concern is related with the use of a RCM, which implies that the lateral boundary conditions could impose a constraint on certain aspects of the coupling. Feedbacks between simulated precipitation and soil moisture anomalies may be dependent on the regional model's domain size (Seth and Rojas, 2003), but this should not be a problem in large domains (such as the one used in this study) that allow interactions with the larger scales (Collini et al., 2008). 


\subsection{Time period and time scales}

Our study covers only the monsoon cycle of 1992-1993. Previous studies (Fu et al., 1999; Collini et al., 2008) have suggested that the surface and dynamical processes of the SAMS act in the monsoon region independently of the large-scale conditions. However, the interannual variability modulates the frequency and intensity of synoptic systems and also the patterns of soil moisture anomalies (i.e. ideally this experiment should be repeated with different boundary forcing).

To examine the CS on a subseasonal but suprasynoptic scale, 6-d means were calculated for the period December 1 to February 28 for each ensemble. This gives a time series of 15 steps for each ensemble member from which CS was calculated for precipitation and evapotranspiration. It should be noticed that other choices of averaging periods (as 3, 4, 5 and 9 d) gave similar results in the location of hotspots. To reduce noise from high precipitation values, the CS was calculated from the natural logarithm of precipitation.

\subsection{The $\Delta \Omega$ index}

The GLACE project defined CS as the difference between the similarity among the members of the ensembles $\mathrm{S}$ and $\mathrm{W}$. The similarity of the variable $\mathrm{X}, \Omega_{\mathrm{X}}$, is a measure of how similar the time series of the ensemble are. It can also be defined as the relative contribution of all boundary conditions on the variability of X.

The $\Omega$ for any atmospheric variable $X$ is

$\Omega_{X}=\frac{m \sigma_{X}^{2}-\sigma_{X}^{2}}{(m-1) \sigma_{X}^{2}}$,

where $\sigma_{\hat{X}}^{2}$ is the variance of the mean time series of all members of one ensemble, $\sigma_{X}^{2}$ is the ensemble intermember variance which is obtained by calculating the variance among all time steps and ensemble members and $m$ is the number of ensemble members. $\Omega_{X}$ is interpreted as the fraction of the variance of $X$ that is explained by boundary conditions (the total variance depends on internal variability of the model and on boundary conditions). The similarity of $X$ is 0 if there is no correlation among ensemble members and 1 if the time series of $X$ are identical for all ensemble members. From this interpretation and from the fact that ensemble $S$ is driven by prescribed soil moisture, we expect that $\Omega$ will be larger for ensemble $S$ in regions were the soil moisture explains some of the variance of the variable $X$. The $\operatorname{CS}\left(\Delta \Omega_{X}\right)$ between soil moisture and $X$ is defined as the difference between the similarities of the two ensembles

$\Delta \Omega_{X}=\Omega_{X}(S)-\Omega_{X}(W)$,

where $\Delta \Omega_{X}$ isolates the soil moisture boundary condition influence on the phase, amplitude and mean value of the variable $X$ (a strict mathematical analysis of the index has been provided by Yamada et al. 2007).

\subsection{The $\Delta \Theta$ index}

Wang et al. (2007) used the same experimental design as described in Section 3.1, but defined the coupling strength index differently than the GLACE project. Wang et al. (2007) argued that their index, called the $\Delta \Theta$ index, is more useful for seasonal predictions, using soil moisture as a predictor. That is, the index $\Delta \Theta$ depend less on phase similarity than the $\Delta \Omega$ index, and more on predictability of mean seasonal precipitation. The interpretation of predictability that will be used here is that regions with high $\Delta \Theta_{X}$ will show less seasonal mean spread of the variable $X$ among the members of ensemble $S$ than among members of ensemble $\mathrm{W}$, since the members of $\mathrm{S}$ are forced by the same soil moisture field. The $\Delta \Theta$ index is based on the intraensemble relative variance averaged across time:

$\Theta_{x}=\frac{1}{15} \sum_{j=1}^{15}\left\{\frac{1}{\bar{X}_{j}^{2}}\left[\frac{1}{10} \sum_{i=1}^{10}\left(X_{i j}-\bar{X}_{j}\right)^{2}\right]\right\}$,

where the outer summation is over time steps of the period of study (in our case 15), and the inner summation is over number of ensemble members (in our case 10 ). $\bar{X}_{j}$ corresponds to the ensemble averaged value of $X$ for time step $j$ and $X_{i j}$ corresponds to the value of ensemble member number $i$ at time step $j$.

In regions of coupling between soil moisture and $X$, the variance should be higher for the $\mathrm{W}$ ensemble than for ensemble $\mathrm{S}$. The fraction of the $\mathrm{W}$ interensemble variance that is explained by soil moisture $-X$ coupling is the $\Delta \Theta$ index:

$\Delta \Theta_{X}=\frac{\Theta_{x}^{W}-\Theta_{x}^{S}}{\Theta_{x}^{W}}$.

\section{Results}

\subsection{The chain soil moisture-evapotranspiration- precipitation using the $\Delta \Omega$ index}

Regions where the precipitation is governed highly by the boundary conditions have a high $\Omega_{\mathrm{P}}$. The influence of the SST and lateral boundary conditions results in high $\Omega_{\mathrm{P}}(\mathrm{S})$ in the ITCZ region (located between the equatorial Andes and the mouth of the Amazon River (near the equator, Fig. 3) and in Patagonia where synoptic systems governs precipitation variance. In regions with low $\Omega_{\mathrm{P}}$, the precipitation variance is governed by model internal variability. In regions where soil moisture does not influence on rainfall, $\Omega_{\mathrm{P}}(\mathrm{W})$ is almost equal to $\Omega_{\mathrm{P}}(\mathrm{S})$ and $\Delta \Omega_{\mathrm{P}}$ is close to zero. Only when $\Omega_{\mathrm{P}}(\mathrm{S})$ is in part governed by soil moisture, $\Delta \Omega_{\mathrm{P}}$ is positive (Fig. 4). The high values around the La Plata Basin, are a result of a high percentage of the boundary forcing coming from the soil moisture conditions. In the figure, negative values are masked with grey. Negative values occur in regions where the soil moisture does not influence on the precipitation and the similarity of the $\mathrm{W}$ ensemble is slightly higher than for the $\mathrm{S}$ ensemble. 

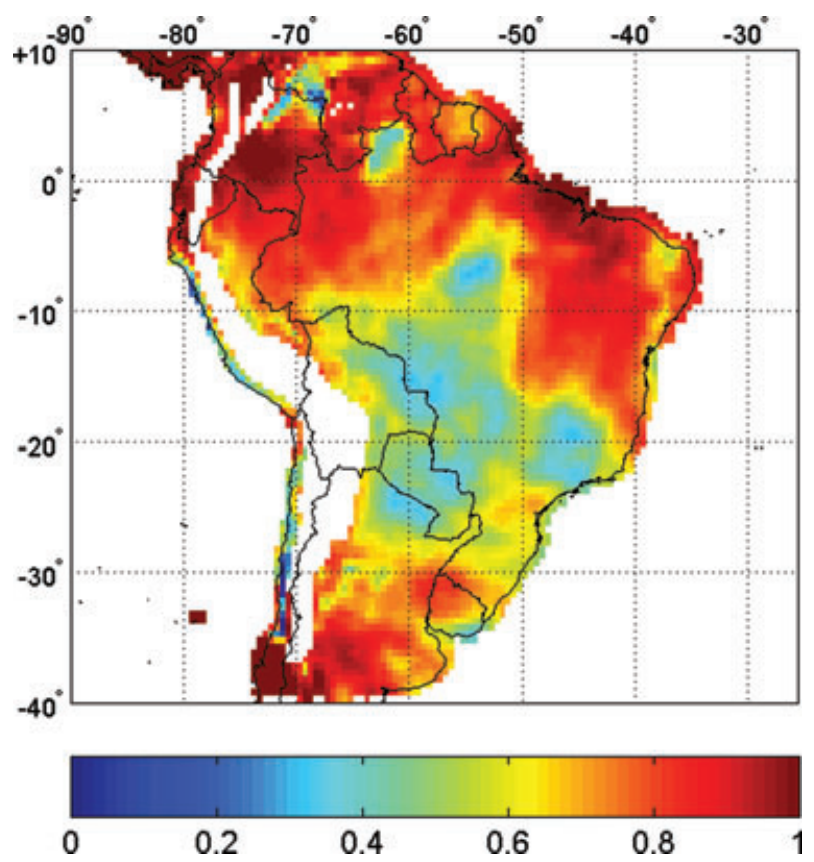

Fig. 3. The similarity of precipitation, $\Omega_{\mathrm{P}}$ of ensemble $\mathrm{S}$ (DJF 1992-1993). The surrounding oceans as well as elevated terrain (above $1500 \mathrm{~m}$ ) are masked with white colour.
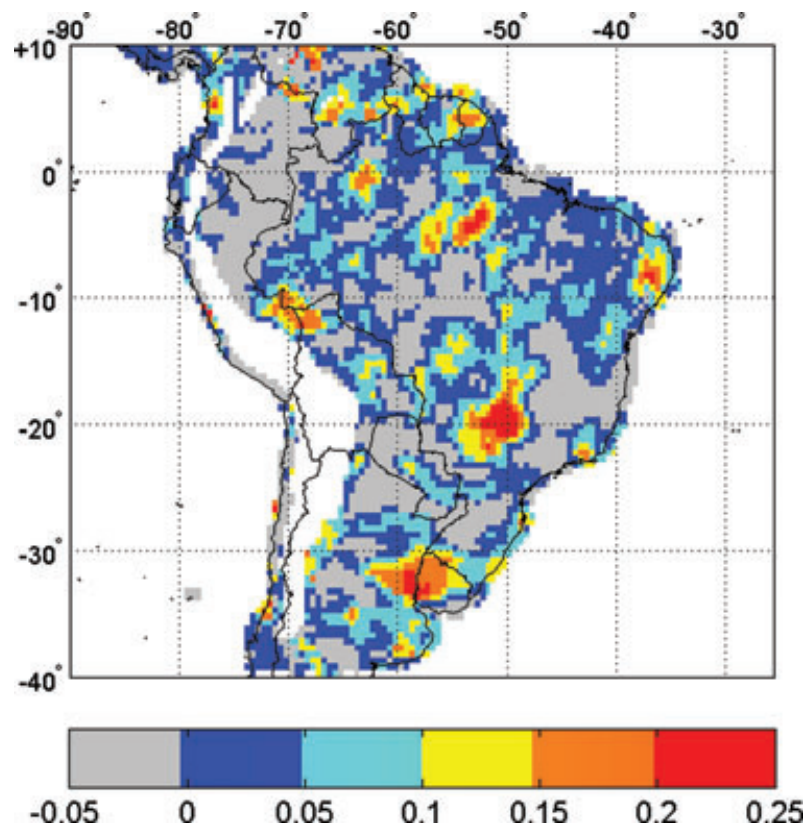

Fig. 4. Coupling strength between soil moisture and precipitation $\Delta \Omega_{\mathrm{P}}$. The surrounding oceans as well as elevated terrain are masked with white colour.

High $\Delta \Omega_{\mathrm{P}}$ can be a result of the feedback chain that connects soil moisture with precipitation through evapotranspiration. This feedback can be a local land surface influence on precipitation, when a soil moisture anomaly at one grid point generates an evapotranspiration anomaly that in its turn generates a rainfall anomaly. In this case, the coupling between soil moisture and evapotranspiration $\left(\Delta \Omega_{\mathrm{E}}\right)$, is high at this grid point. It can also be a remote influence, when the moisture in the boundary layer is provided mainly by transport from upstream. In the calculations of CS, which are made grid point by grid point, it is impossible to separate these two processes.

A necessary, but not sufficient, condition for the local chain soil moisture-evapotranspiration-precipitation not to be 'broken' is not only a high $\Delta \Omega_{\mathrm{E}}$, but also a high variance of evapotranspiration $\left(\sigma_{\mathrm{E}}\right)$. This is because without a high variance of evapotranspiration, the evapotranspiration changes induced by soil moisture anomalies will not be sufficiently high to generate precipitation through direct processes (Guo et al., 2006). The CS between soil moisture and evapotranspiration, $\Delta \Omega_{\mathrm{E}}$, and the product $\Delta \Omega_{\mathrm{E}}{ }^{*} \sigma_{\mathrm{E}}$ are shown in Fig. 5 . The product is related to the soil moisture content. In Fig. 6 the product is binned by soil water availability (SWA), which is a variable that is calculated on basis of amount of top and deep soil moisture and on the soil properties, and has values between 0 (wilting point) and 1 (field capacity). $\Delta \Omega_{\mathrm{E}}{ }^{*} \sigma_{\mathrm{E}}$ has maximum values for small to intermediate values of SWA (0.2-0.4). For dry regions with low SWA, $\Delta \Omega_{\mathrm{E}}$ is high since the atmosphere is dry and the evapotranspiration is not limited by high atmospheric moisture content. However, the $\sigma_{\mathrm{E}}$ is small, since the amounts of precipitation are small. For wet soils, the coupling between soil moisture and evapotranspiration is weak, since the evapotranspiration is limited by the high near surface humidity, and consequently the product $\Delta \Omega_{\mathrm{E}}{ }^{*} \sigma_{\mathrm{E}}$ is low.

Comparing the Figs. 4 and 5b, the central La Plata Basin and northeastern Brazil have both high $\Delta \Omega_{\mathrm{P}}$ and high $\Delta \Omega_{\mathrm{E}}{ }^{*} \sigma_{\mathrm{E}}$. In regions where $\Delta \Omega_{\mathrm{P}}$ is low although the $\Delta \Omega_{\mathrm{E}}{ }^{*} \sigma_{\mathrm{E}}$ is high, as for example in Northwestern Argentina, the coupling between evapotranspiration and precipitation is low. This coupling cannot be quantified directly through the experiments in the present study, but could only be calculated through performing two ensembles employing evapotranspiration (instead of soil moisture) as boundary conditions. However, through the present experiments, it is possible to identify grid points with low evapotranspiration-precipitation coupling roughly as points with high $\Delta \Omega_{\mathrm{E}}{ }^{*} \sigma_{\mathrm{E}}$ and low $\Delta \Omega_{\mathrm{P}}$.

Conversely, there are areas with a weak coupling between soil moisture and evapotranspiration and high values of $\Delta \Omega_{\mathrm{P}}$. This can be explained by the fact that evapotranspiration is a variable of a much higher local character than precipitation. As highlighted in the introduction, coupling strength at each grid point are a result of the boundary forcing from the entire soil moisture field. Since the evapotranspiration at a grid point, 'A', is a local process, the relative influence of the soil moisture at grid points surrounding A on the evapotranspiration at A, will be small in comparison to the influence of the soil moisture at $\mathrm{A}$. In the case of precipitation, the contribution of the soil moisture of grid points around A could have a much higher 

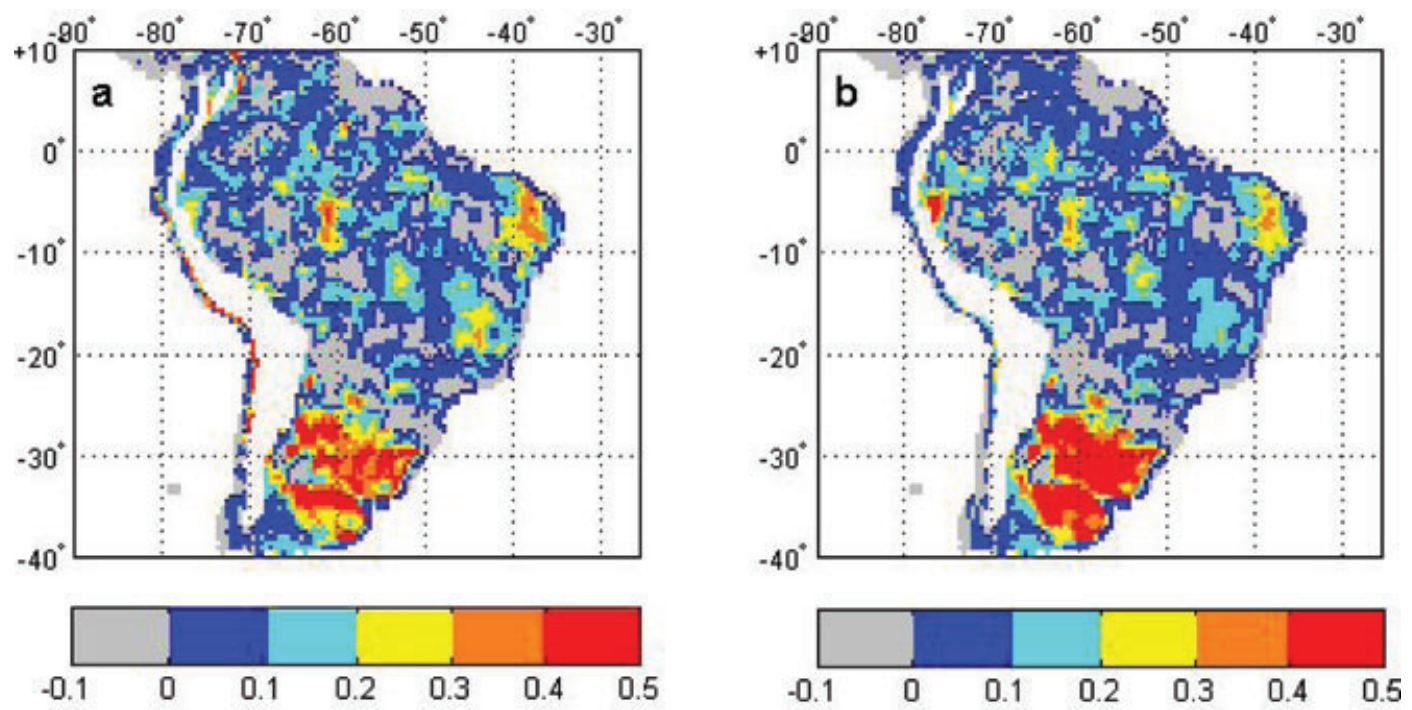

Fig. 5. Evapotranspiration: (a) Coupling strength between soil moisture and evapotranspiration $\Delta \Omega_{\mathrm{E}}$. (b) The product of the coupling strength between soil moisture and evapotranspiration and the standard deviation of evapotranspiration $\Delta \Omega_{\mathrm{E}}{ }^{*} \sigma_{\mathrm{E}}$. The surrounding oceans as well as elevated terrain are masked with white colour.

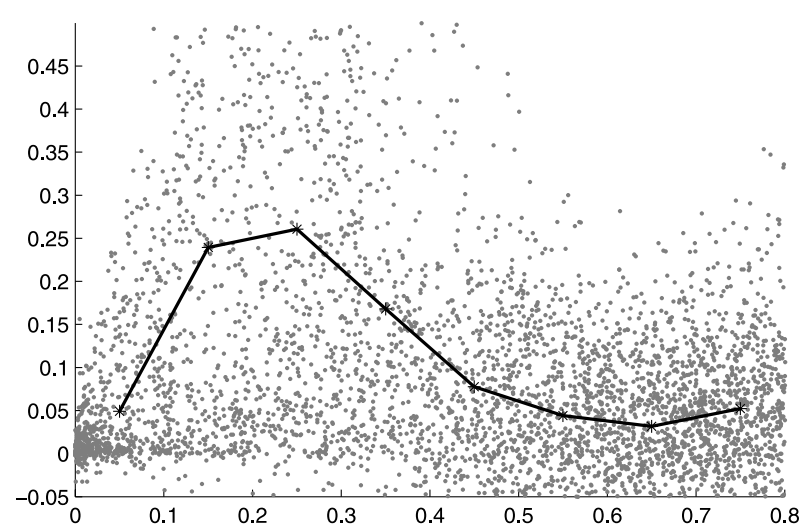

Fig. 6. The product of the coupling strength between soil moisture and evapotranspiration and the standard deviation of evapotranspiration $\Delta \Omega_{\mathrm{E}}{ }^{*} \sigma_{\mathrm{E}}$ binned by soil water availability (SWA). The $x$-axes corresponds to SWA in percentage of saturation and the $y$-axes corresponds to $\Delta \Omega_{\mathrm{E}}{ }^{*} \sigma_{\mathrm{E}}$.

influence through advection of moisture to A. One region where this happens is the hotspot of $\Delta \Omega_{\mathrm{P}}$ around $20^{\circ} \mathrm{S}, 50^{\circ} \mathrm{W}$, which is a region within the South Atlantic Convergence Zone (SACZ), where $\Delta \Omega_{\mathrm{E}}{ }^{*} \sigma_{\mathrm{E}}$ is low. This is a region of strong convergence of moisture, and the moisture could originate from soil moisture anomalies upstream.

\subsection{The $\Delta \Theta$ index}

The geographical distribution of the CS soil moistureevapotranspiration calculated with the $\Delta \Theta$ index $\left(\Delta \Theta_{\mathrm{E}}\right.$, Fig. 7) is similar to the $\Delta \Omega_{\mathrm{E}}$ index. According to Wang et al. (2007) the advantage of the $\Delta \Theta$ index compared to the $\Delta \Omega$ index is that

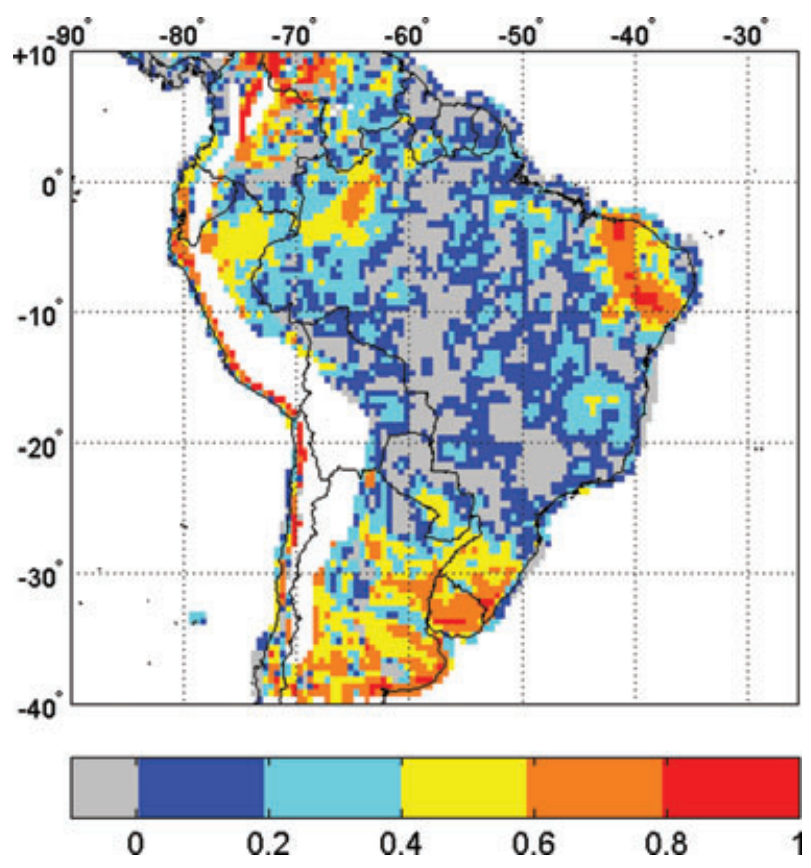

Fig. 7. Coupling strength between soil moisture and evapotranspiration $\Delta \Theta_{\mathrm{E}}$. The surrounding oceans as well as elevated terrain are masked with white colour.

it expresses seasonal predictability to a higher degree than the $\Delta \Omega$ index, while the $\Delta \Omega$ index depends to a higher degree on phase similarity. Here, seasonal predictability is understood as small spread of the seasonal ensemble mean evapotranspiration, [we measure the spread by the standard deviation of the ensemble means, $\left.\sigma_{\mathrm{DJF}}(\mathrm{E})\right]$. In a region with high $\Delta \Omega_{\mathrm{E}}, \sigma_{\mathrm{DJF}}(\mathrm{E})$ of ensemble $\mathrm{S}$ should be lower than for ensemble $\mathrm{W}$, since the soil 


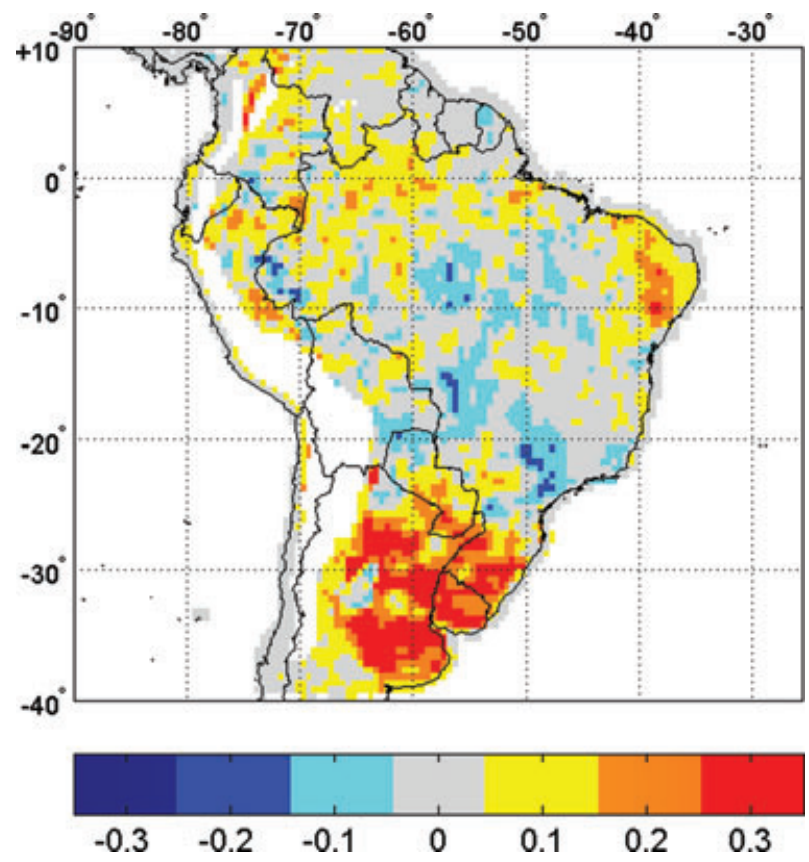

Fig. 8. Difference between mean seasonal spread $\sigma_{\mathrm{DJF}}(\mathrm{E})$ computed as the standard deviation of mean evaporation from ensemble $\mathrm{W}$ and $\mathrm{S}$. Unit: $\mathrm{mm} \mathrm{d}^{-1}$. The surrounding oceans as well as elevated terrain are masked with white colour.

moisture in $\mathrm{S}$ is equal for all ensemble members. This definition of seasonal predictability is motivated by the practical use that knowledge of soil moisture could have for seasonal predictions over regions with large soil moisture-atmosphere coupling. The difference between $\sigma_{\mathrm{DJF}}(\mathrm{E})$ of the two ensembles is displayed in Fig. 8. From a visual comparison of this figure with $\Delta \Theta_{\mathrm{E}}$ (Fig. 7) and $\Delta \Omega_{\mathrm{E}}$ (Fig. 5a), it is clear that the ensemble $\mathrm{W}$ has a higher seasonal spread than $S$ in regions with high $\Delta \Theta_{\mathrm{E}}$ and $\Delta \Omega_{\mathrm{E}}$, in this experiment, both indices indicate seasonal predictability.

The soil moisture-precipitation coupling, $\Delta \Theta_{\mathrm{P}}$, in Fig. 9, shows a very different pattern than the $\Delta \Omega_{\mathrm{P}}$, and is highly noisy. Furthermore, most grid points show negative values of $\Delta \Theta_{P}$. From eq. 4, negative $\Delta \Theta_{\mathrm{P}}$ is a consequence of $\Theta^{\mathrm{S}}$ being larger than $\Theta^{\mathrm{W}}$. Examining eq. 3, $\Theta^{\mathrm{S}}>\Theta^{\mathrm{W}}$ can imply that the variance of $\mathrm{S}$ is larger than the variance of $\mathrm{W}$, as can occur as a result of internal variability at grid points where precipitation is not influenced by the forcing soil moisture field of ensemble S. Another situation that produces a negative $\Delta \Theta_{\mathrm{P}}$ is when the $\bar{X}_{j}:$ s of ensemble $\mathrm{S}$ are of less magnitude than the $\bar{X}_{j}:$ s of ensemble W. Since the $\bar{X}_{j}$ :s correspond to the ensemble averaged value of $\mathrm{X}$ for time step $j$, this would indicate that the seasonal mean of ensemble $\mathrm{S}$ is of less magnitude than for ensemble $\mathrm{W}$. Another property of the $\Delta \Theta$ index worth noting is that for grid points with negative (positive) $\Theta^{\mathrm{W}}-\Theta^{\mathrm{S}}$, the absolute values of $\Delta \Theta_{\mathrm{E}}$ are higher (smaller) as a consequence of dividing with a smaller (higher) $\Theta^{\mathrm{W}}$. To give an illustration of how the temporal behavior of the precipitation can be at grid points with differ-

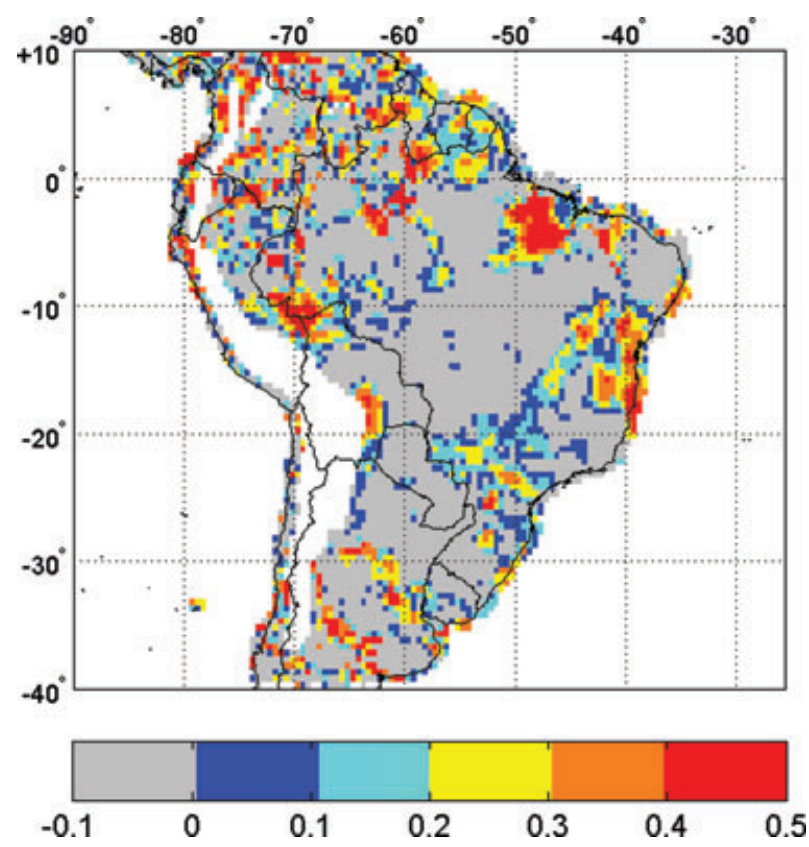

Fig. 9. Coupling strength between soil moisture and precipitation $\Delta \Theta_{\mathrm{P}}$. The surrounding oceans as well as elevated terrain are masked with white colour.

ent values of $\Delta \Theta_{\mathrm{P}}$ and $\Delta \Omega_{\mathrm{P}}$, one point with positive and one with negative $\Delta \Theta_{\mathrm{P}}$ were randomly selected $\left(35.5^{\circ} \mathrm{S}, 67^{\circ} \mathrm{W}\right.$ with $\Delta \Theta_{\mathrm{P}}=0.51$ and $16.5^{\circ} \mathrm{S}, 55^{\circ} \mathrm{W}$ with $\left.\Delta \Theta_{\mathrm{P}}=-0.52\right)$. Both grid points have low but positive $\Delta \Omega_{\mathrm{P}}\left(\Delta \Omega_{\mathrm{P}}=0.066\right.$ and 0.086 , respectively). The time series of both ensemble 6-d averaged precipitation are displayed in Fig. 10. In the case of the grid point of positive $\Delta \Theta_{\mathrm{P}}$, and low but positive $\Delta \Omega_{\mathrm{P}}$, there is not much difference between the phase correlation of the $\mathrm{S}$ and $\mathrm{W}$ time series. The maximum amplitude difference is higher in ensemble S, but on the other hand, only for a few of the members and for two out of fifteen time steps. The seasonal ensemble mean of $\mathrm{S}\left(\mathrm{SEM}_{\mathrm{P}}(\mathrm{S})\right)$ is slightly higher than $\operatorname{SEM}_{\mathrm{P}}(\mathrm{W})$ (2.37 and $2.22 \mathrm{~mm} \mathrm{~d}^{-1}$, respectively). In the case of the second grid point, it is more directly visible why the $\Delta \Omega_{\mathrm{P}}$ is positive-the time series of $\mathrm{S}$ is clearly more both phase and amplitude correlated than the $\mathrm{W}$ series. However, it seems like $\Delta \Theta_{\mathrm{P}}$ is negative because of the lower $\operatorname{SEM}_{\mathrm{P}}(\mathrm{S})\left(\operatorname{SEM}_{\mathrm{P}}(\mathrm{S})=6.50\right.$ and $\operatorname{SEM}_{\mathrm{P}}(\mathrm{W})=$ 7.91). To confirm this, in Fig. $11 \mathrm{a}, \Delta \Theta_{\mathrm{P}}$ of all grid points are binned by $\operatorname{SEM}_{\mathrm{P}}(\mathrm{S})-\mathrm{SEM}_{\mathrm{P}}(\mathrm{W})$. The $\Delta \Theta_{\mathrm{P}}$ index clearly depends on small seasonal mean precipitation differences between the ensembles. This could be seen as a deficiency of the $\Delta \Theta_{P}$ index of the present experiment, since differences in seasonal mean precipitation between the two ensembles should not be important for the CS. To compare, $\Delta \Omega_{\mathrm{P}}$ is binned by $\operatorname{SEM}_{\mathrm{p}}(\mathrm{S})-$ $\mathrm{SEM}_{\mathrm{p}}(\mathrm{W})$ in Fig. $11 \mathrm{~b}$, and it is clear that $\Delta \Omega_{\mathrm{P}}$ is not sensitive to small differences in the seasonal mean precipitation. In this experiment the number of ensemble members was limited to 10 , and it is possible that employing larger ensembles smooth out 

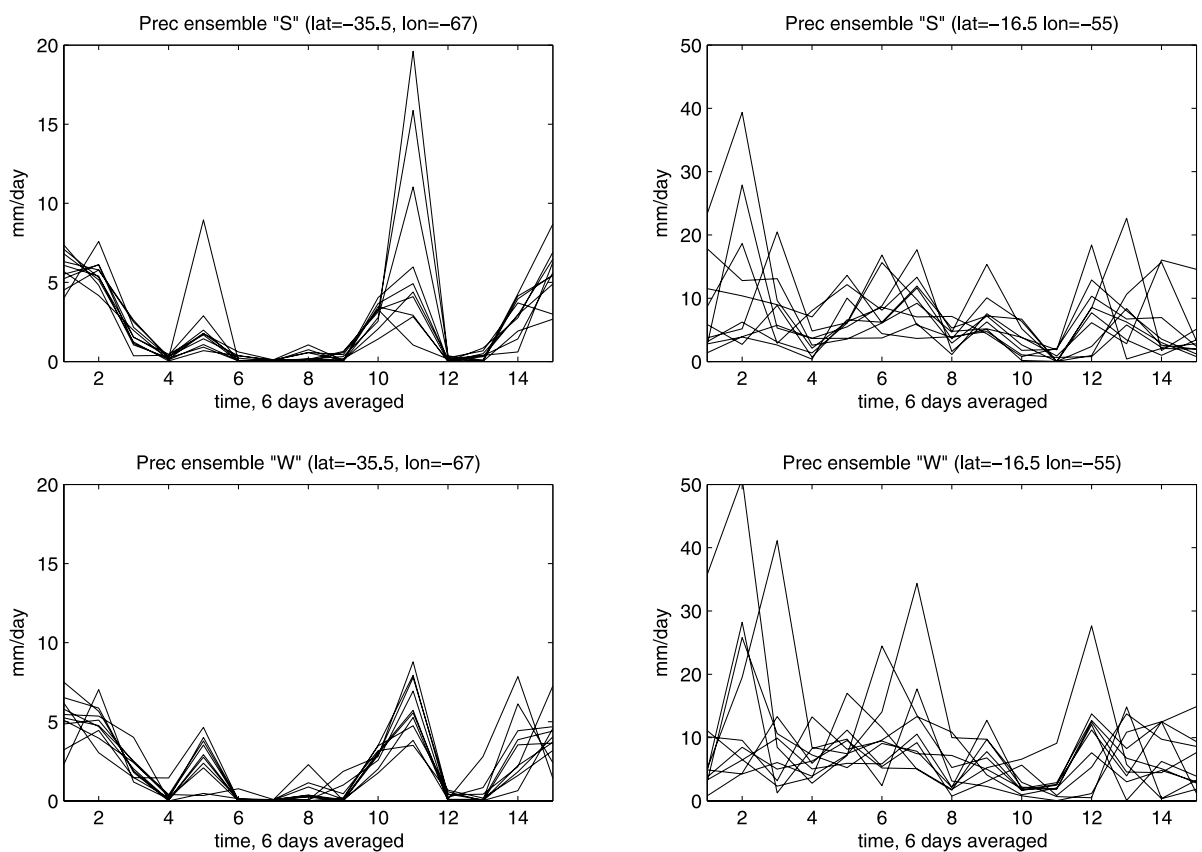

Fig. 10. The time series of precipitation (6-d means) for left-hand panel—point with positive $\Delta \Theta_{\mathrm{P}}$ and right-hand panel—point with negative $\Delta \Theta_{\mathrm{P}}$, upper panel: ensemble $\mathrm{S}$, lower panel ensemble W. Unit: $\mathrm{mm} \mathrm{d}^{-1}$.

the differences in seasonal mean between ensemble $\mathrm{S}$ and $\mathrm{W}$. For the present experiment with a limited ensemble, we considered that the $\Delta \Omega_{\mathrm{P}}$ index is more appropriate to estimate the CS soil moisture-precipitation, and since its properties can be explained physically the index seems to be a useful measure.

\subsection{Relationship between extreme precipitation and $\Delta \Omega$ index}

The interest in focusing on a possible relationship between land surface processes and extreme precipitation events is motivated by the following factors: (i) The strongest convective storms are often found over land in semiarid regions (Zipser et al., 2006); (ii) Analysis of the global models within the GLACE project by Guo et al. (2006) revealed that the coupling soil moisture-convective precipitation was higher than the coupling soil moisture-total precipitation; and (iii) Our results suggest a hotspot of strong coupling between soil moisture and both evapotranspiration and precipitation in southern La Plata Basin, a region characterized by high rainfall extremes associated with mesoscale convection (Velasco and Fritsch, 1987).

Here, $\Delta \Omega_{\mathrm{E}}$ and $\Delta \Omega_{\mathrm{P}}$ will be compared to the fraction of precipitation due to heavy precipitation events. The fraction is measured by calculating the 95th percentile of the wet days precipitation divided by the total seasonal precipitation. This extreme precipitation index (EPI, displayed for ensemble $S$ in Fig. 12) is a measure of how important the severe precipitation events are in comparison to the total seasonal mean and contains some information on the precipitation regime. Severe rainfall, as represented by this index, has a rather different geographical distribution than mean total precipitation or conventional measures of convective activity (e.g. average outgoing long-wave radiation). The rainiest parts of the regional monsoon in central South America have numerous events of strong rains but relatively few severe storms (i.e. EPI displays a minimum over this region). The main regions with high EPI are southeastern South America (southern La Plata Basin) and northwestern South America (Colombia and Venezuela). Interestingly, the first region coincides with the high coupling strength area for evapotranspiration (see $\Delta \Omega_{\mathrm{E}}$ in Fig. 5a). In contrast, the coupling strength over Colombia and Venezuela is very low (similarly, the arid South American west coast and northern Patagonia show up as regions with high EPI and low $\Delta \Omega_{\mathrm{E}}$ ). This suggests that extreme precipitation events in northern South America are not influenced by feedbacks from the ground, but that heavy rainfall around the Rio de la Plata may be partly related to these processes.

In order to further explore the possible relation between soil moisture feedbacks and extreme precipitation, we compare the extreme index calculated from ensembles S and W (Fig. 13). Both ensembles give very similar results over most regions, except over areas of high EPI. Parts of northern South America and Patagonia and the Pacific coast are characterized by a nonuniform and patchy distribution of EPI(S) - EPI(W), further confirming that soil moisture feedbacks are not connected to extreme events in these regions.

Southeastern South America is a region with a well defined pattern of EPI(S) - EPI(W). The EPI is higher in ensemble W over the Uruguay's hotspot, an area with high $\Delta \Omega_{\mathrm{P}}$ due to local 

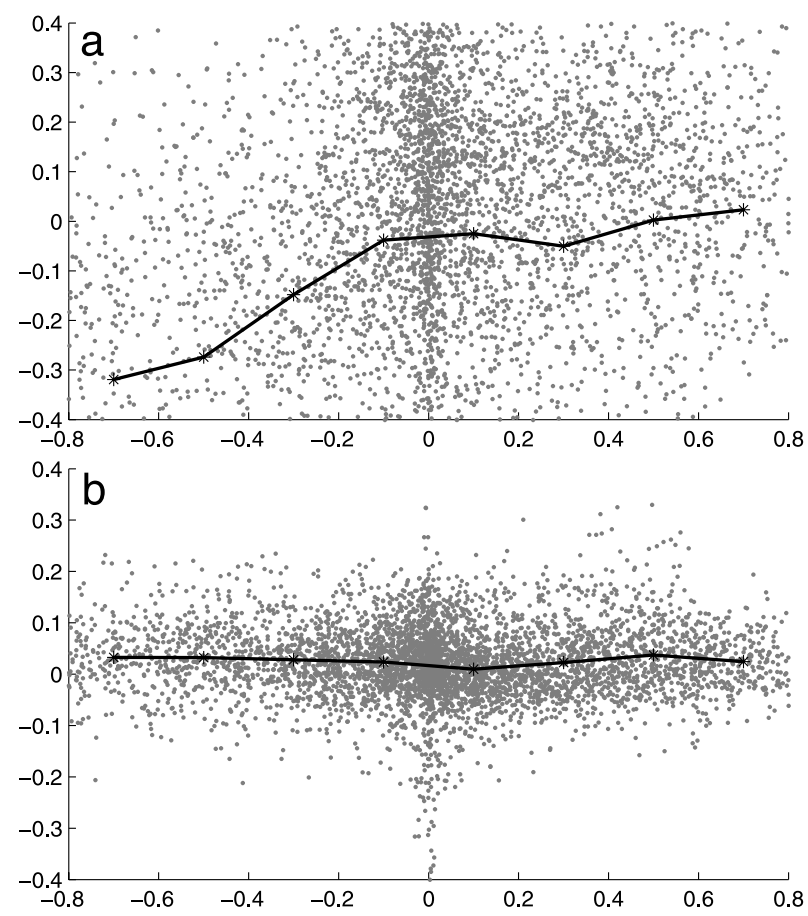

Fig. 11. The coupling strength of precipitation binned by the difference between the seasonal mean precipitation of ensemble $S$ and ensemble W: $\operatorname{SEM}_{\mathrm{P}}(\mathrm{S})-\mathrm{SEM}_{\mathrm{P}}(\mathrm{W})$. (a) $\Delta \Theta_{\mathrm{P}}$ and (b) $\Delta \Omega_{\mathrm{P}}$. $X$-axis difference in precipitation in $\mathrm{mm} \mathrm{d}^{-1}$ and $y$-axis the corresponding coupling strength index.

evapotranspiration recycling. On the other hand, this index is higher in ensemble $\mathrm{S}$ over large areas of northern and central Argentina, a region with high $\Delta \Omega_{\mathrm{E}}$ but low $\Delta \Omega_{\mathrm{P}}$.

A fundamental question is whether we can understand conceptually why EPI(W) $>$ EPI(S) over Uruguay and why EPI(W) $<$ EPI(S) over parts of Argentina. Two main contrasting physical mechanisms may be invoked to explain such a difference. The feedback between soil moisture and the subsequent occurrence of convective rainfall may be either positive or negative (Taylor and Ellis, 2006; Alfieri et al., 2008). A positive feedback has been suggested by Eltahir (1998): high soil moisture values induce a decrease in the Bowen ratio, thus favouring convective instability, and hence the triggering of convective rain. The fact that ensemble $\mathrm{W}$, which has a complete soil moisture-atmosphere coupling, presents higher EPI at the hotspot suggests that a positive feedback is dominant over Uruguay. In contrast, a negative feedback has been proposed in Taylor and Ellis (2006) and Cook et al. (2006): surface fluxes from wet soils are associated with surface cooling and the possible stabilization of the planetary boundary layer, thereby leading to subsidence. In this case, convective initiation occurs preferentially over dry soils. This mechanism is plausible to be dominant over parts of Argentina where $\Delta \Omega_{\mathrm{P}}$ coupling is weak but $\Delta \Omega_{\mathrm{E}}$ coupling is high.

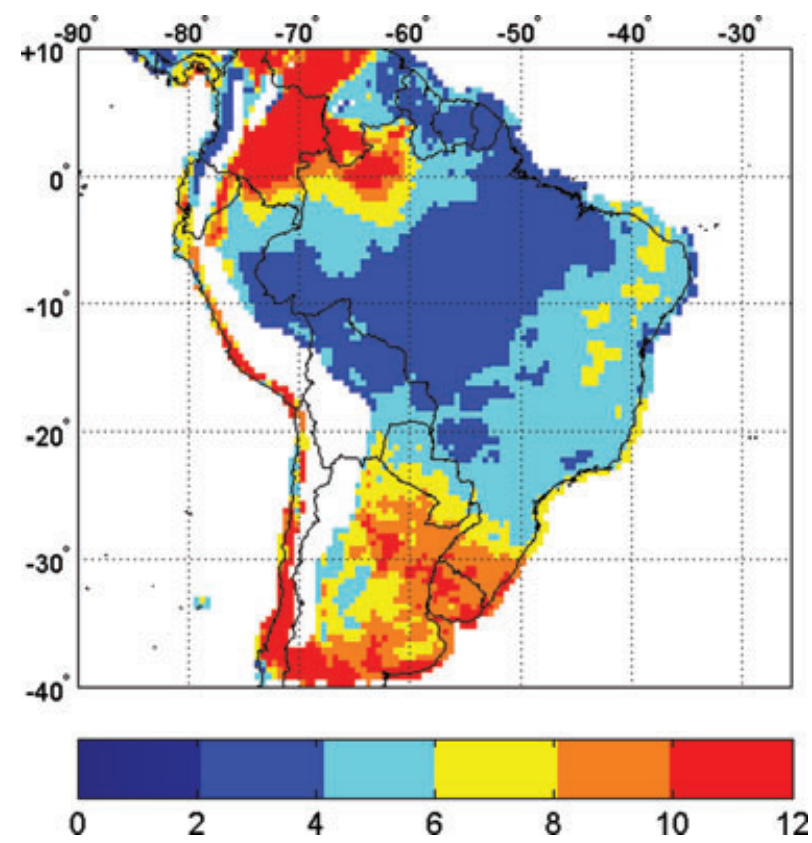

Fig. 12. The extreme precipitation index (EPI) of ensemble $\mathrm{S}$ (fraction of 95th percentile rainfall contribution to total rainfall in per cent). The surrounding oceans as well as elevated terrain are masked with white colour.

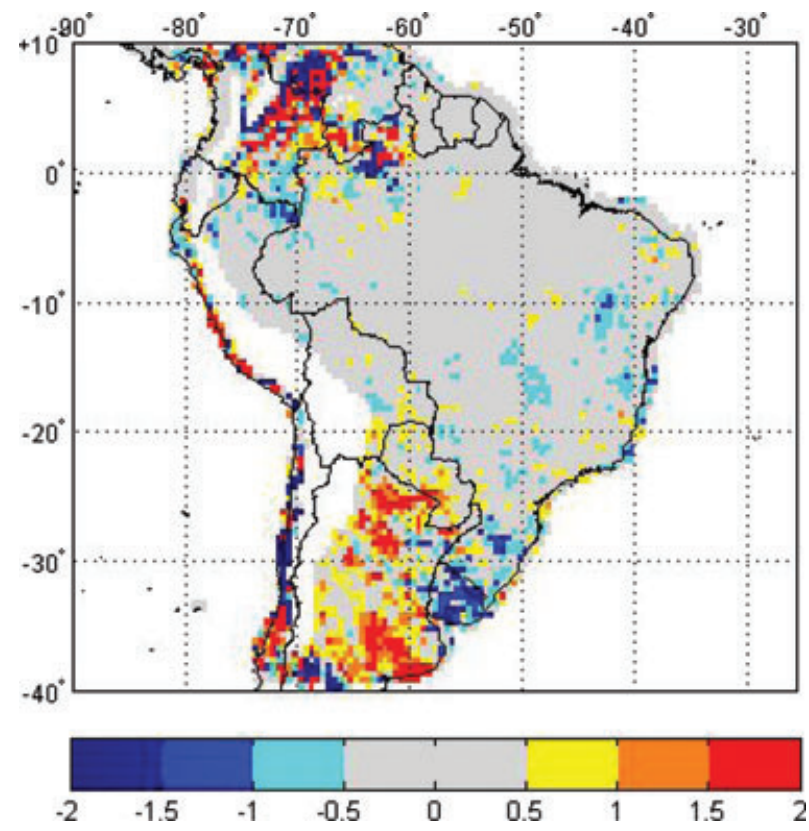

Fig. 13. The difference between extreme precipitation index of the two ensembles: $\operatorname{EPI}(\mathrm{S})$ - EPI(W) (per cent). The surrounding oceans as well as elevated terrain are masked with white colour.

Both mechanisms may occur during the warm season leading to a complex local climatology in which the feedback between soil moisture and subsequent heavy precipitation occurrence is difficult to detect (Alfieri et al., 2008). Moreover, the sensitivity 
of convective initiation to soil moisture depends not only on surface processes. The stability of the layer into which the boundary layer is growing is considered to be important for determining the sign of the feedback (Ek and Mahrt, 1994). Other mechanisms for enhancement of mesoscale convective precipitation (Ruane and Roads, 2007) include (i) Land's evaporative potential and heat capacity allow for fast variations in atmospheric stability and convective available potential energy affecting mesoscale convection and (ii) Sharp horizontal gradients in land characteristics lead to more rapid intensifications and moderation of existing lower-frequency storms as they pass over the region.

These results only provide a first approach to the hypothesized relation between soil moisture and intense rainfall in southern La Plata Basin. Further diagnostics (e.g. diurnal cycle) with a larger sample size and using different models are required to confirm our results.

\section{Final remarks}

Process-based studies of regional scale features driving the climate system is an important component for interpreting climate models results and assessing the strengths and weaknesses of dynamical downscaling. However, the comprehension of the physical basis of simulated variability and changes is not always readily apparent given the complexity of the processes involved. Precipitation is generated through interactions of dynamical atmospheric advection, convergence, and lifting mechanisms, as well as thermodynamic processes such as moisture availability and thermal stability. Land surface conditions feed back on atmospheric conditions and in particular on precipitation through the partitioning of surface fluxes. In some geographic areas these feedbacks could be similar or stronger than other processes.

With this in mind, we examine the impacts of soil moisture conditions on rainfall generation through calculating the coupling strength between soil moisture and evapotranspiration and precipitation with a RCM over South America for the austral summer season. The study isolates the aspects related to the locally forced component of evapotranspiration and precipitation (that is, climate variability arising from the interactions with the continental surface) and constitutes a partial contribution towards process-based understanding of features driving the climate system at the regional scale.

The geographical distribution of precipitation coupling strength, $\Delta \Omega_{\mathrm{P}}$, for South America reveals large regions with relatively weak or non-uniform random values while some main hotspots-regions with high $\Delta \Omega_{\mathrm{p}}$-could be identified. The main hotspot of strong coupling between land and both evapotranspiration and precipitation is located near the Rio de la Plata in South Eastern South America. The breakdown of the coupling mechanism into two segments- the link between soil moisture and evapotranspiration and the link between evapotranspiration and precipitation-helps to identify some of the reasons for the geographical distribution of the hotspots. Evapotranspira- tion rates are sensitive to soil moisture in dry climates but not in wet climates where it is partially controlled by atmospheric demand. However, a strong coupling with precipitation benefits from high atmospheric moisture variability as found in wet climates but not in dry climates. In consequence, in transition zones between wet and dry conditions (like in parts of La Plata Basin), where evapotranspiration variations are suitably high but are still sensitive to soil moisture, the land states tend to have relatively strong impacts on precipitation. A part of the SACZ region was also found to be a mayor hotspot, however, this region has low evapotranspiration variation and a low $\Delta \Omega_{\mathrm{E}}$ and could not be attributed to local recycling. Since this is a region of strong moisture convergence, the high $\Delta \Omega_{\mathrm{P}}$ could be a result of moisture advection originated from soil moisture anomalies upstream. The magnitude of the $\Delta \Omega_{\mathrm{P}}$ and $\Delta \Omega_{\mathrm{E}}$ is comparable with the results of Koster et al. (2006) and Guo et al. (2006) for boreal summer using global models. Wang et al. (2007) calculated CS with a global model for DJF and their hotspots of $\Delta \Omega_{\mathrm{P}}$ coincides with two hotspots found in this study, the La Plata Basin and Norteastern Brazil.

Another concern of this research was to relate the influence of the land-atmosphere coupling on the occurrence of extreme precipitation. For this purpose, we use an extreme precipitation index (EPI) defined as the fraction of the total seasonal precipitation that is due to the 95th percentile of daily precipitation (similar to R95t in Frich et al., 2002). The regional spatial patterns of EPI are well correlated with the regions of strong coupling between soil moisture and evapotranspiration (as characterized by the diagnostic product $\Delta \Omega_{\mathrm{E}}{ }^{*} \sigma_{\mathrm{E}}$ ) over large areas of South Eastern South America. However, the feedback between soil moisture and subsequent heavy precipitation occurrence may be either positive or negative. Comparing the EPI for the $\mathrm{S}$ ensemble with that for the $\mathrm{W}$ ensemble, the latter is noticeably stronger over Uruguay, a region approximately coincident with the main hotspot area in southern La Plata Basin. The fact that extreme precipitation is enhanced in the hotspot if the model includes a complete land surface-atmosphere interaction suggests that a positive feedback is dominant over regions of high $\Delta \Omega_{\mathrm{P}}$. On the contrary, extreme precipitation events tend to be favoured when soil moisture is prescribed in the model (ensemble $S$ ) over parts of Argentina where $\Delta \Omega_{\mathrm{E}}{ }^{*} \sigma_{\mathrm{E}}$ coupling is high but $\Delta \Omega_{\mathrm{P}}$ coupling is weak suggesting a negative feedback. The fact that the extreme rainfall events prefer regions of strong land-evapotranspiration coupling corroborates the previously noted connections between convective precipitation and land surface moisture variations (Emori 1998; Guo et al., 2006).

Provided the existence of relatively strong soilevapotranspiration-precipitation feedbacks in summer over areas of La Plata Basin some conclusion can be drawn concerning seasonal prediction and regional climate change assessment. First, initial soil moisture conditions provide 'memory' to climate system's predictability and are more important than the initial atmospheric conditions at seasonal 
prediction time scales (e.g. Lawford et al., 2007). This needs to be especially recognized for the hotspots areas. Second, since not all land-atmosphere interactions are currently fully resolved in models and considering the non-linearities in the climate system, it is difficult to assess how these feedbacks may alter the downscaled climate projection for regions with high CS.

RCMs suffer relatively low skill in reproducing the daily precipitation intensity distributions over South Eastern South America (Menéndez et al., 2010). In general, precipitation falls too frequently but intensities are too light. The frequency of strong and heavy precipitation events is underestimated by models (including RCA3-E). This deficiency seems related to uncertainties in physics parametrizations. For example, convective parametrizations being too strongly dependent on non local driving mechanisms, lead to reduced mesoscale activity but longer periods of light precipitation (Ruane and Roads, 2007). As southern La Plata Basin is a region with relatively high CS, a realistic representation of the land-atmosphere interaction would be particularly critical. A complex combination of several factors is required for improving models' performance including proper land surface characterization, high resolution (both horizontal and vertical, the number of soil layers influence on the soil moisture memory which in turn affects the precipitation variability; Ruane and Roads, 2007) and the use of good-quality databases for initializing and driving surface parameters (e.g. roughness length, vegetation fraction, leaf area index, albedo, rooting depth; Masson et al., 2003). These aspects affect models' feedbacks and deserve further assessment and development so that the land-precipitation coupling and the daily intensity distribution of precipitation can be simulated realistically in La Plata Basin. Such a skill is important to give confidence of the model-simulated climate sensitivity or climate change scenarios.

Finally some caveats on this study are as follows. We must caution against generalizing the results of this paper as the experiments have been restricted to one single regional model and one single season. The CS patterns for the $\mathrm{NH}$ evaluated with global models were very different among different models (Koster et al., 2004, 2006), suggesting that repeating our experiment with other RCMs could lead to different patterns over Southern America as well. Probably part of the intermodel variability in coupling patterns derived from global models was due to limited sampling of only one single season, which is also the case in this study. In order to address the realism of RCA3-E's coupling strength more simulations under different seasons are needed and, in addition, it would be useful to determine how it compares with other RCMs in this region.

\section{Acknowledgments}

The research leading to these results has received funding from the European Community's Seventh Framework Programme (FP7/2007-2013) under Grant Agreement N 212492 (CLARIS LPB. A Europe-South America Network for Climate Change As- sessment and Impact Studies in La Plata Basin). PIP-CONICET 112-200801-01788 (Argentina) also supported this work. A.A. Sörensson has a grant from Rossby Centre, Swedish Meteorological and Hydrological Institute (SMHI). This work was begun while A.A Sörensson visited SMHI in Norrköping, Sweden, invited by the Rossby Centre and with financial support from SMHI and CLARIS. Simulations were carried out on Tornado at the National Supercomputer Center in Linköping, Sweden, and at the Centro de Investigaciones del Mar y la Atmósfera in Buenos Aires, Argentina. We acknowledge the Climatic Research Unit, University of East Anglia, UK for providing the precipitation data and the European Centre for Medium Range Weather Forecast (ECMWF) for providing the ERA-40 data set to the CLARIS Project. Thanks to Ulf Hansson for technical support and to Patrick Samuelsson and Jan Polcher for valuable discussions, and to the valuable comments from the two reviewers.

\section{References}

Alfieri, L., Claps, P., D’Odorico, P., Laio, F. and Over, T.M. 2008. An analysis of the soil moisture feedback on convective and stratiform precipitation. J. Hydrometeor. 8, 280-291.

Betts, A. K. and Viterbo, P. 2005. Land-surface, boundary layer, and cloud-field coupling over the southwestern Amazon in ERA-40. J. Geophys. Res. 110, D14108, doi:10.1029/2004JD005702.

Champeaux, J.L., Masson, V. and Chauvin, F. 2005. ECOCLIMAP: a global database of land surface parameters at $1 \mathrm{~km}$ resolution. Met. Appl. 12, 29-32.

Chen C., Cotton, W.R. 1987. The physics of the marine stratocumuluscapped mixed layer. J. Atmos. Sci. 44, 2951-2977.

Collini, E.A., Berbery, E.H., Barros, V.R. and Pyle, M.E. 2008. How does soil moisture influence the early stages of the South American monsoon? J. Climate. 2, 195-213.

Cook, B. I., Bonan, G. and Levis, S. 2006. Soil moisture feedbacks to precipitation in southern Africa. J. Climate. 19, 4198-4206.

Dirmeyer, P.A. 2003. The role of the land surface background state in climate predictability. J. Hydrometeor. 4, 599-610.

Dirmeyer, P.A., Koster, R.D. and Guo, Z. 2006. Do global models properly represent the feedback between land and atmosphere? J Hydrometeor. 7, 1177-1198.

Ek, M. and Mahrt, L. 1994. Daytime evolution of relative humidity at the boundary layer top. Mon. Wea. Rev. 122, 2709-2721.

Eltahir, E.A.B. 1998. A soil moisture-rainfall feedback mechanism. 1. Theory and observations. Water Resour. Res. 34, 765-776.

Eltahir, E.A.B. and Bras, R.L. 1994. Precipitation recycling in the Amazon basin. Quart. J. Roy. Meteor. Soc. 120, 861-880.

Eltahir, E.A.B. and Bras, R.L. 1996. Precipitation recycling. Rev. Geophys. 34, 367-378.

Emori, S. 1998. The interaction of cumulus convection with soil moisture distribution: an idealized simulation. J. Geophys. Res. 103(D8), 8873-8884.

Frich, P., Alexander, L.V., Della-Marta P., Gleason B., Haylock M. and co-authors. 2002. Observed coherent changes in climatic extremes during the second half of the twentieth century. Clim. Res. 19, 193-212. 
Fu, R., Zhu, B. and Dickinson, R.E. 1999. How do atmosphere and land surface influence seasonal changes of convection in the tropical Amazon? J. Climate. 12. 1306-1321.

$\mathrm{Fu}, \mathrm{R}$. and Li, W. 2004. The influence of the land surface on the transition from the dry to wet season in Amazonia. Theor. Appl. Climatol 78, 97-110.

Guo, Z., Dirmeyer, P.A., Koster, R.D., Bonan, G., Chan, E. and coauthors. 2006. GLACE: the global land-atmosphere coupling experiment. Part II: analisis. J. Hydrometeor. 7, 611-625.

Juang, J. Y., Katul, G.G., Porporato, A., Stoy, P.C., Siqueira, M.S. and coauthors. 2007. Eco-hydrological controls on summertime convective rainfall triggers. Global Change Biol. 13, 887-896.

Kain, J.S. 2004. The Kain-Fritsch convective parameterization: an update John S. Kain. J. Appl. Meteorol. 43, 170-181.

Kain, J.S. and Fritsch, J.M. 1993. Convective parameterizations for MEsoscale Models: the Kain-Fritsch scheme. In: The Representation of Cumulus Convection in Numerical Models Volume 46 (eds K.A. Emanuel and D.J. Raymond. AMS Monograph, 246.

Khairoutdinov, M. F. and Kogan, Y.L. 2000. A new cloud physics parameterization in a large-eddy simulation model of marine stratocumulus. Mon. Wea. Rev. 128, 229-243.

Koster, R.D., Guo, Z. and Dirmeyer, P.A. 2003. GLACE: quantifying land-atmosphere coupling strength across a broad range of climate models. CLIVAR Exchanges. 28, 1-3.

Koster, R.D., Dirmeyer, P.A., Guo, Z., Bonan, G., Chan, E. and coauthors. 2004. Regions of strong coupling between soil moisture and precipitation. Science. 305, 1138-1140.

Koster, R.D., Guo, Z., Dirmeyer, P.A., Bonan, G., Chan, E. and coauthors. 2006. GLACE: the global land-atmosphere coupling experiment. Part I: overview. J. Hydrometeror. 7, 590-610.

Lawford, R. G., Roads, J., Lettenmaier, D. P. and Arkin, P. 2007. GEWEX contributions to large-scale hydrometeorology. J. Hydrometeror, 8, 629-641.

Li, W. and Fu, R. 2004. Transition of the large-scale atmospheric and land surface conditions from the dry to the wet season over Amazonia as diagnosed by the ECMWF re-analysis. J. Climate. 17, 2637-2651.

Masson, V., Champeaux, J.-L., Chauvin, F., Meriguet, C. and Lacaze, R. 2003. A global database of land surface parameters at 1-km resolution in meteorological and climate models. J. Climate. 16. 1261-1282.

Menéndez, C.G., de Castro, M., Boulanger, J.-P., D’Onofrio, A., Sanchez, E. and co-authors. 2010. Downscaling extreme month-long anomalies in southern South America. Climatic Change. 98, 379-403.

New, M., Hulme, M. and Jones, P. 1999. Representing twentieth-century space time climate variability. Part I. development of a 1961-1990 mean monthly terrestrial climatology. J. Climate. 12, 829-856.

New, M., Hulme, M. and Jones, P. 2000. Representing twentiethcentury space time climate variability. Part II: development of 1901-1996. monthly grids of terrestrial surface climate. J. Climate. 13, 2217-2238.

Nogués-Paegle, J., Mechoso, C.R., Fu, R., Berbery, E.H., Chao, W.C. and co-authors. 2002. Progress in Pan American CLIVAR research: understanding the South American monsoon. Meteorologica 27, 1-30.
Rogers, R.F. and Fritschv J.M. 1996. A general framework for convective trigger functions. Mon. Wea. Rev. 124, 2438-2452.

Ruane, A.C. and Roads, J.O. 2007. 6-hour to 1-year variance of five global precipitation sets. Earth Interact., 11, doi:10.1175/EI225.1

Samuelsson, P., Jones, C., Willén, U., Gollvik, S., Hansson, U. and coauthors. 2011. The Rossby Centre Regional Climate Model RCA3: model description and performance. Tellus 63A, 4-23.

Seneviratne, S. I., Lüthi, D., Litschi, M. and Schär, C. 2006. Land-atmosphere coupling and climate change in Europe. Nature 443, 205-209.

Seth, A. and Rojas, M. 2003. Simulation and sensitivity in a nested modeling system for South America. Part I: Reanalyses boundary forcing. J. Clim. 16, 2437-2453.

Silva, V. B. S. and Berbery, E. H. 2006. Intense rainfall events affecting the La Plata basin. J. Hydrometeor. 7, 769-787.

Sörensson, A.A., Samuelsson, P., Willén, U., Menéndez, C.G., 2009. The importance of surface boundary forcing for simulated South American climate. In: Proceedings of the iLEAPS-GEWEX Early Career Scientist Workshop, 20-22 of August, Melbourne, Australia. (Available at: http://www.atm.helsinki.fi/uploads/ileapsjoomla/dmdocuments/ ECSW\%20Proceedings.pdf).

Sörensson, A.A. 2010. Analysis of Land Surface-Atmospheric Feedbacks in South America using a New Regional Climate Model. $\mathrm{PhD}$ thesis. Universidad de Buenos Aires.

Taylor, C. M. and Ellis, R. J. 2006. Satellite detection of soil moisture impacts on convection at the mesoscale. Geophys. Res. Lett. 33, doi:10.1029/2005GL02525.

Trenberth, K.E. 1999. Atmospheric moisture recycling: role of advection and local evaporation. J. Climate. 12, 1368-1381.

Uppala, S.M., Kållberg, P.W., Simmons, A.J., Andrae, U., da Costa Bechtold, V. and co-authors. 2005. The ERA-40 re-analysis. Quart J. R. Meteorol. Soc. 131, 2961-3012.

Velasco, I. and Fritsch, J.M. 1987. Mesoscale convective complexes in the Americas. J. Geophys. Res. 92(D8), 9591-9613.

Vera, C., Higgins, W., Amador, J., Ambrizzi, T., Garreaud, R. and coauthors. 2006a. Toward a unified view of the American monsoon systems. J. Climate. 19, 4977-5000.

Vera, C., Silvestri, G., Liebmann, B. and Gonzalez, P. 2006b. Climate change scenarios for seasonal precipitation in South America from IPCC-AR4 models. Geophys. Res. Lett. 33. L13707, doi:10.1029/2006GL025759.

Wang, G., Kim, Y. and Wang, D. 2007. Quantifying the strength of soil moisture-precipitation coupling and its sensitivity to changes in surface water budget. J. Hydrometeorol. 8, 551-570.

Webster, P. J., Magana, V., Palmer, T.N., Shukla, J., Tomas, R.A. and coauthors. 1998. Monsoons: processes, predictability, and the prospects for prediction. J. Geophys. Res. 103(C7), 14451-14510.

Yamada, T.J., Koster, R.D., Kanae, S. and Oki, T. 2007. Estimation of predictability with a newly derived index to quantify similarity among ensemble members. Mon. Wea. Rev. 135, 2674-2687.

Zipser, E. J., Cecil, D. J., Liu, C., Nesbitt, S. W. and Yorty, D. P. 2006. Where are the most intense thunderstorms on Earth?. Bull. Am. Meteorol. Soc. 87, 1057-1071. 